\title{
Pregnane X-receptor promotes stem cell-mediated colon cancer relapse
}

\author{
Chris Planque ${ }^{1,2,3, *}$, Fatemeh Rajabi, ${ }^{1,2,3, *}$, Fanny Grillet ${ }^{1,2,3}$, Pascal Finetti ${ }^{4}$, François \\ Bertucci $^{4}$, Meritxell Gironella ${ }^{5}$, Juan José Lozano ${ }^{5}$, Bertrand Beucher ${ }^{1,2,3}$, Julie \\ Giraud $^{1,2,3}$, Véronique Garambois ${ }^{6}$, Charles Vincent ${ }^{6}$, Daniel Brown ${ }^{7}$, Ludovic \\ Caillo $^{1,2,3}$, Jovana Kantar ${ }^{8}$, André Pelegrin ${ }^{6}$, Michel Prudhomme ${ }^{9}$, Jérémie Ripoche ${ }^{9}$, \\ Jean François Bourgaux ${ }^{10}$, Christophe Ginestier ${ }^{11}$, Antoni Castells ${ }^{5}$, Frédéric

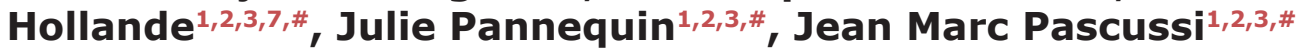 \\ ${ }^{1}$ CNRS UMR5203, Institut de Génomique Fonctionnelle, Montpellier, France \\ ${ }^{2}$ INSERM U1191, Montpellier, France \\ 3 Université Montpellier, Montpellier, France \\ ${ }^{4}$ Centre de Recherche en Cancérologie de Marseille, INSERM UMR1068, CNRS UMR725, Marseille, France \\ ${ }^{5}$ Centro de Investigación Biomédica en Red de Enfermedades Hepáticas y Digestivas (CIBEREHD), Institut d'Investigaciones \\ Biomèdiques August Pi i Sunyer (IDIBAPS), Barcelona, Spain \\ ${ }^{6}$ Institut de Recherche en Cancérologie de Montpellier, Montpellier, France \\ ${ }^{7}$ Department of Pathology, University of Melbourne, Parkville, Australia \\ ${ }^{8}$ Laboratoire de Biochimie, CHU Carémeau, Nîmes, France \\ ${ }^{9}$ Service de Chirurgie Digestive, CHU Carémeau, Nîmes, France \\ ${ }^{10}$ Service d'Hépato-Gastroentérologie, CHU Carémeau, Nîmes, France \\ ${ }^{11}$ Centre de Recherche en Cancérologie de Marseille, U1068 Inserm, Marseille, France \\ *These authors have contributed equally to this work \\ \#These authors jointly supervised the work \\ Correspondence to: Frédéric Hollande, email: frederic.hollande@unimelb.edu.au \\ Jean Marc Pascussi, email: jean-marc.pascussi@inserm.fr
}

Keywords: PXR, colorectal cancer, cancer stem cell, tumor recurrence

Published: July 18, 2016

\section{ABSTRACT}

Colorectal cancer lethality usually results from post-treatment relapse in the majority of stage II-IV patients, due to the enhanced resistance of Cancer Stem Cells (CSCs). Here, we show that the nuclear receptor Pregnane X Receptor (PXR, NR1I2), behaves as a key driver of CSC-mediated tumor recurrence. First, PXR is specifically expressed in CSCs, where it drives the expression of genes involved in self-renewal and chemoresistance. Clinically, high levels of PXR correlate with poor recurrence-free survival in a cohort of $>200$ stage II/III colorectal cancer patients treated with chemotherapy, for whom finding biomarkers of treatment outcome is an urgent clinical need. shRNA silencing of PXR increased the chemo-sensitivity of human colon CSCs, reduced their self-renewal and tumor-initiating potential, and drastically delayed tumor recurrence in mice following chemotherapy. This study uncovers PXR as a key factor for CSC self-renewal and chemoresistance and targeting PXR thus represents a promising strategy to minimize colorectal cancer relapse by selectively sensitizing CSCs to chemotherapy. 


\section{INTRODUCTION}

Colorectal cancer (CRC) is the third most commonly diagnosed cancer, which causes 655,000 deaths annually worldwide [1]. To this day systemic chemotherapy cocktails (5-fluorouracil (5-FU), irinotecan, and oxaliplatin) that target the bulk population of proliferative tumor cells remain the cornerstone of treatment for advanced CRC [2]. However, treatment efficiency is severely hampered by the frequent occurrence of drugresistance and post-treatment tumor recurrence. In recent years, highly tumorigenic sub-populations of cancer cells, named Cancer Stem Cells (CSCs), have been implicated in post-treatment tumor recurrence [3]. These cells are characterized by the expression of stem cell factors that endow them with stemness properties, such as the ability to self-renew. They are capable of initiating and sustaining tumor growth in serial transplantation assays [4, 5]. In addition, they are notably characterized by a higher capacity to resist treatments compared to other tumor cells $[6,7]$. Evidence from xenograft models [8] and human trials [9] indicate selective enrichment of CSCs in CRC tumors that survive therapy.

Given that CSCs are the chief culprits in the failure of current therapies, it is important to identify innovative approaches that target them to improve clinical outcomes for cancer patients. To date, most strategies aim to inhibit CSC self-renewal or to induce their differentiation [10]. However, these phenotypic traits are shared by healthy adult stem cells, leading to specific concerns about potential side effects. An alternative CRC therapy would be to sensitize CSCs to current therapies, but the precise mechanism underlying the higher drug resistance of CSCs remains unclear. Multiple parameters have been proposed to be involved in CSC drug resistance, including slow proliferation, increased resistance to DNA damage, activation of anti-apoptosis mechanisms, but also expression of multidrug transporters such as ATP-binding cassette G2 (ABCG2 [11]) and of drug metabolizing enzymes including aldehyde dehydrogenase 1A1 (ALDH1A1 [12]) and the cytochrome P450 CYP3A4 [13]. Accordingly, flow cytometry strategies based on ABCG2 expression (Side Population, SP) and ALDHactivity (Aldefluor-'bright' cells or ALDH ${ }^{\text {br }}$ ) have been used to identify CSCs in various types of solid tumors including CRC $[14,15]$. SP cells and ALDH ${ }^{\text {br }}$ cells are also characterized by an enhanced chemoresistance to various cytotoxics $[16,17,8]$. Consequently, these populations are enriched following chemotherapy $[8,16]$.

We previously reported that the orphan nuclear receptor PXR (Pregnane X Receptor, NR1I2), a key regulator of xenobiotic metabolism in the liver [18], increased irinotecan resistance in CRC cell lines [19]. Since PXR has been previously described to regulate CYP3A4 gene expression in human hepatocytes [18], and Aldh1a1 and Abcg2 genes in mice [20] and porcine
[21] tissues respectively, we hypothesized that PXR may participate in the intrinsic chemoresistance of CSCs. Here, we demonstrate that PXR expression and activity are indeed highly restricted to CSCs, where it drives the expression of a large network of genes that are instrumental for CSC chemoresistance in vitro and in vivo. Furthermore, we observed that PXR and its targets form a prognostic indicator for CRC relapse. These results pinpoint PXR as a clinically druggable Achilles' heel for CSCs in colorectal and potentially also in other cancers.

\section{RESULTS}

\section{PXR expression and activity define chemoresistant colon cancer stem cells}

We compared PXR expression in CSCs versus non-CSCs by using enrichment of self-renewing cells (i.e. spheroids passaging). Previous studies showed that under defined conditions, CRC cells maintained as floating spheroids display enhanced expression of cancer stem cell markers, increased self-renewal and resistance to chemotherapeutic drugs [16]. We confirmed those observations in patient-derived CRC cells (CRC1) maintained as spheroids (Sphe) compared to cells maintained in adherent conditions and exposed to serumcontaining medium (2D). As shown, cells isolated from spheroids had a higher proportion of cells with ALDH activity (Aldefluor positive ('bright') cells, ALDH ${ }^{\text {br }}$, Figure 1a). In addition, they had enhanced spheroid-forming efficiency (Figure 1b), a widely used in vitro assay for CSC quantification [7], calculated as the percentage of seeded cells that gave rise to a spheroid. Moreover, cells maintained as spheroids had a greater resistance to a combination of 5-FU and SN38 (hereafter named "Firi" as SN38 is the active metabolite of irinotecan), when compared to the same cells maintained as adherent monolayers $(\approx 2$-fold increase in $\mathrm{EC}_{50}, \mathrm{p}<0.01$; Figure 1c). RT-qPCR analyses revealed the higher expression of PXR in spheroids compared to 2D conditions as well as an enriched expression of colon CSCs markers (ALDH1A1, Oct-4 [22] and LGR5 [23]) and PXR target genes (CYP3A4 and ABCG2) (Figure 1d). Similar results were obtained in other tested human CRC cell lines (Figure 1e) and patient-derived CRC cells (Supplementary Figure S1a). In addition, both PXR protein expression and PXR transcriptional activity, measured using a PXR luciferase reporter gene [24], were higher in spheroids compared to adherent (2D) conditions (Figure 1f, 1g). Finally, serial passaging of spheroids (passages 1 to 8, i.e. S1 to S8) resulted in the gradual and concomitant enrichment of spheroid-forming efficiency, of $\mathrm{ALDH}^{\mathrm{br}}$ cell percentage and of mRNA expression of CSC markers, correlating tightly with the up regulation of PXR (Supplementary Figure S1b-S1d). Taken together these findings indicate that PXR is preferentially expressed and active in self-renewing colon CSCs. 
a

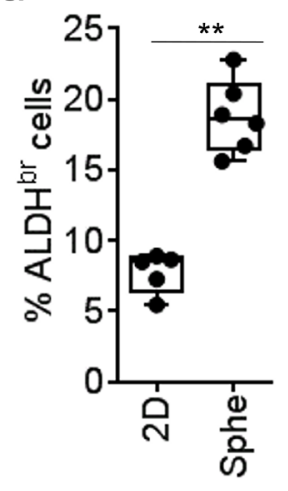

b

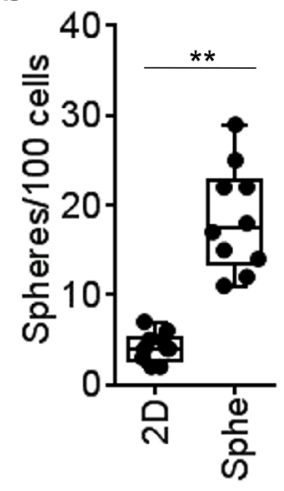

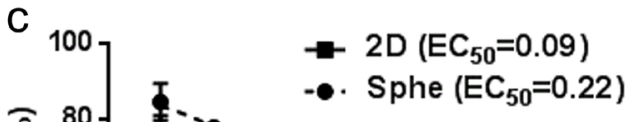

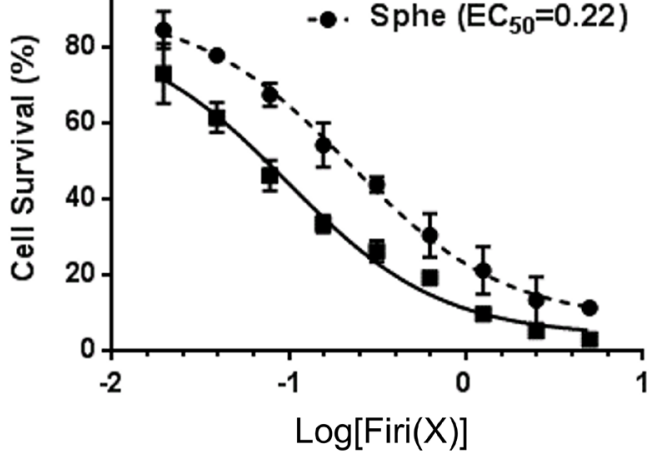

d

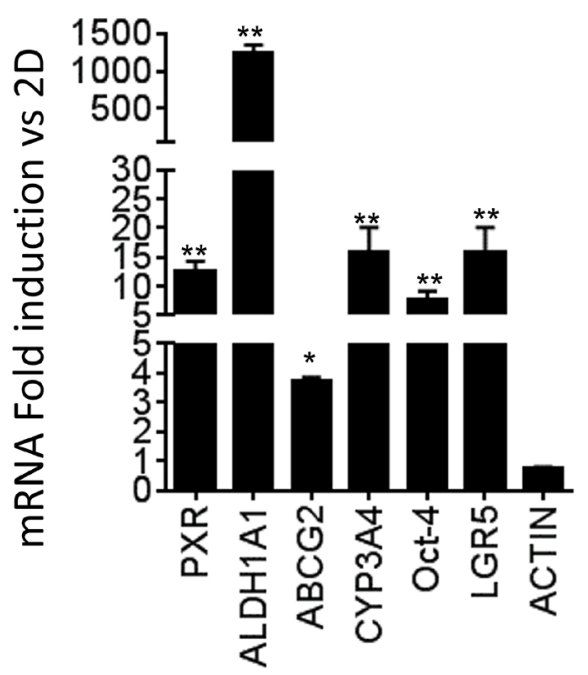

e

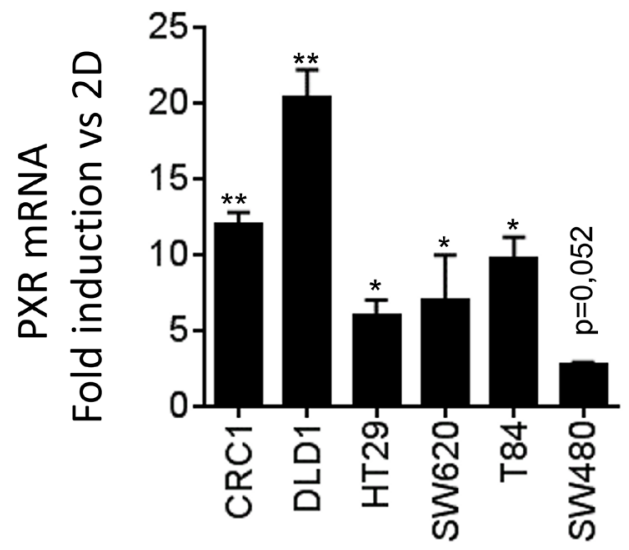

f

g

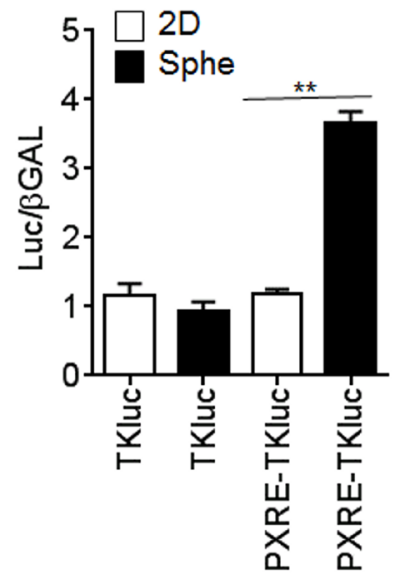

Figure 1: PXR expression is increased in colorectal spheroid models. a. Percentage of ALDH ${ }^{\text {br }}$ cells, and $\mathbf{b}$. percentage of Sphere-Forming Cells of patient-derived CRC cells (CRC1) grown as adherent (2D) or colonosphere (Sphe) cultures. c. Percentage of $\mathrm{CRC1}$ surviving cells 72 hours after exposure to the indicated concentrations of Firi ( $1 \mathrm{X}=50 \mu \mathrm{M} 5$-FU + 500nM SN38). Data are expressed as mean $\pm \mathrm{SEM}$ of 3 experiments, and half maximal effective concentrations $\left(\mathrm{EC}_{50}\right)$ are indicated. d. RT-qPCR analyses of mRNA expression for PXR, PXR target and CSC marker genes in CRC1 cells maintained as Spheroids compared to 2D conditions (F.I., Fold Induction). e. RT-qPCR quantification of PXR mRNA in CRC cell lines maintained as Spheroids compared to 2D conditions. $d, e$, : Data are expressed as mean \pm SEM $(n>3)$ and reported as fold change compared to cells grown in 2D conditions. f. Western-blot analysis of PXR expression in $\mathrm{CRC} 1$ cells maintained as Spheroids compared to 2D conditions. Data are expressed as mean $\pm \mathrm{SEM}(\mathrm{n}=3)$ of PXR/GAPDH ratio. g. PXR transcriptional activity was determined in $\mathrm{CRC} 1$ cells after transfection with luciferase reporter plasmids. Data are expressed as mean \pm $\operatorname{SEM}(\mathrm{n}=3)$ of luciferase/ $\beta$-Galactosidase ratio, normalized to $2 \mathrm{D}$ conditions. *, $\mathrm{p}<0.05 ;{ }^{* *}, \mathrm{p}<0.005$. 
We then isolated CSCs using fluorescence-activated cell sorting based on the activity of Aldefluor. Aldefluor activity and ALDH1A1 gene expression have been described as colon CSC markers [12, 25] and the latter is a regulator of chemoresistance [17, 26, 27] and cell renewal [28]. First, we confirmed that the enhanced Aldefluor activity $\left(\mathrm{ALDH}^{\mathrm{br}}\right.$, Figure $\left.2 \mathrm{a}\right)$ was indeed associated with the specific expression of the ALDH1A1 mRNA isoform in CRC cells (Supplementary Figure S2a, S2b). CRC1 ALDH ${ }^{\text {br }}$ cells had greater spheroid-forming efficiency (Figure 2b) and they were more resistant to Firi treatment $(\approx 6.8$-fold higher $\mathrm{EC}_{50}, \mathrm{p}<0.01$; Figure $2 \mathrm{c}$ ) than $\mathrm{ALDH}^{\mathrm{lo}}$ cells. As shown on Figure 2d, PXR mRNA was strongly enriched in the $\mathrm{ALDH}^{\mathrm{br}}$ population. Similar results were obtained in other tested CRC cell lines (Figures 2e and Supplementary Figure S1b). PXR protein expression was only detected in the $\mathrm{ALDH}^{\mathrm{br}}$ population (Figure 2f), which expectedly had higher ALDH1A1 mRNA and protein levels (Figures 2d, 2f, and Supplementary Figure S2a, S2b). In addition, luciferase reporter genes for PXR transcriptional activity were specifically increased in $\mathrm{ALDH}^{\mathrm{br}}$ cells (Figures $2 \mathrm{~g}$ and Supplementary Figure S2c, S2d), indicating that PXR is preferentially expressed and active in colon $\mathrm{ALDH}^{\text {br }}$ cells.

To validate the preferential expression and activity of PXR in chemoresistant CSCs, we infected T84 cells with a GFP-tagged PXR-driven promoter (CYP3A4eGFP) to selectively sort cells according to their PXR activity level (Figure 3a); cells transduced with an EIF1 $\alpha$-driven eGFP construct were used as control. We first validated the reporter system by comparing the expression of PXR and its target genes in cell populations sorted according to their GFP expression level. Cells with high PXR activity (i.e. CYP3A4eGFP ${ }^{\text {br }}$ ) had higher PXR, CYP3A4 and ABCG2 mRNA expression (Figure $3 b)$. Furthermore, CYP3A4eGFP ${ }^{\text {br }}$ cells had enhanced expression of colon CSC markers such as ALDH1A1, Oct-4 and LGR5. In addition, CYP3A4eGFP ${ }^{\text {br }}$ cells had higher resistance towards Firi treatment (Figure 3c). Finally, CYP3A4eGFP br cells had higher sphere-forming efficiency (Figure 3d) and a ten-fold higher stem cell frequency (as calculated according to $\mathrm{Hu}$ et al. [29]) ( $1 / 9 \pm 3$ for CYP3A4 ${ }^{\text {br }}$ cells vs $1 / 94 \pm 32$ for CYP $3 A 4^{\text {lo }}$ cells, $\mathrm{p}=0.002$ ) compared to CYP3A4eGFPlo cells. Accordingly, flow cytometry analyses showed a specific increase of cells with strong PXR activity after CSC selection, by spheroid passaging or Firi treatment (Figure 3e). Together these data demonstrate that PXR transcriptional activity tracks chemo-resistant CSCs.

\section{PXR regulates a large network of CSC resistance genes and of poor prognosis factors in colon cancer patients treated with chemotherapy}

Having established the preferential expression and activity of PXR in colon CSCs, we then directly assessed the impact of PXR down-regulation on both chemoresistance and mRNA expression profile of patientderived $\mathrm{ALDH}^{\text {br }}$ cells transfected with PXR siRNA (Supplementary Table S1 for siRNA sequences). First, we observed that $\mathrm{ALDH}^{\text {br }}$ cell survival was significantly decreased after transfection with an efficient siRNA sequence decreasing PXR expression (see Supplementary

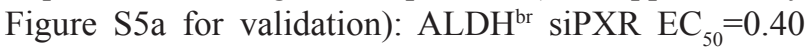
compared to $\mathrm{ALDH}^{\text {br }}$ sißGAL $\quad \mathrm{EC}_{50}=0.83 \quad(\mathrm{p}<0.01$, Figure 4a). Microarray experiments showed that, 48 hours after transfection, the expression of 374 genes was significantly altered by PXR down-regulation in $\mathrm{ALDH}^{\mathrm{br}}$ cells (Supplementary Table S2 and Figure 4b). Notably, PXR-depletion led to the down-regulation of CSC markers such as ALDH1A1 [12], OLFM4 [30], and LRIG-1 [31] and the up-regulation of differentiation markers such as MUC2 (goblet cells) and FABP1 (enterocytes). A Gene Ontology analysis highlighted that PXR depletion in $\mathrm{ALDH}^{\mathrm{br}}$ cells down-regulates the DNA damage sensor and repair machinery (known to help CSCs to overcome many standard anticancer treatments [32]), while it promotes the expression of genes involved in apoptosis and cell death (Supplementary Figure S3). GSEA analyses based on a clinical study describing outcome-related gene signatures in groups of patients homogeneously treated with 5-FUbased chemotherapy [33], showed that down-regulated genes in $\mathrm{ALDH}^{\mathrm{br}}$ cells, following PXR depletion, were specifically enriched in a poor progression-free survival signature. Conversely, genes that were up-regulated in PXR-depleted cells were enriched in the good-prognosis signature (Figure 4c). Similar results were observed after PXR gain-of function in two different LS174T clones (i.e. LS PXR2 and LS PXR6; Supplementary Figure S4a) in which microarray (Supplementary Table S3) and RT-qPCR validation analyses (Supplementary Figure S4b) confirmed that over-expression of PXR regulates the expression of multiple colon CSC markers (ALDH1A1, ABCG2, CYP3A4, CD24 [34], CXCR4 [35], LRIG-1 and OLFM4) and prognostic markers for colorectal tumor recurrence (ABCC6 [36] and S100A10 [37]). Again, GSEA analyses showed that genes with significantly higher expression levels in LS PXR2 and LS PXR6 cells were specifically enriched in the poor-prognosis signature [33] (Figure 4d). Together these results indicate that PXR controls the expression of a large gene network associated with CSC phenotype and post-chemotherapy tumour recurrence.

Since ALDH1A1 appeared as one of the top-ranked differentially regulated genes after PXR up-regulation or inhibition (Supplementary Tables S2\&S3) and has been described as key CSC marker $[12,25]$ and a poor prognosis factor in colon cancer patients [38], we focused our attention on its putative regulation by PXR. First, gain- and loss-of function in LS174T cells confirmed that the expression of ALDH1A1 mRNA and protein was positively regulated by PXR (Figure 5a, 5b). In addition, the proportion of $\mathrm{ALDH}^{\mathrm{br}}$ cells was enhanced in PXRoverexpressing cells and strongly decreased upon PXR 
a

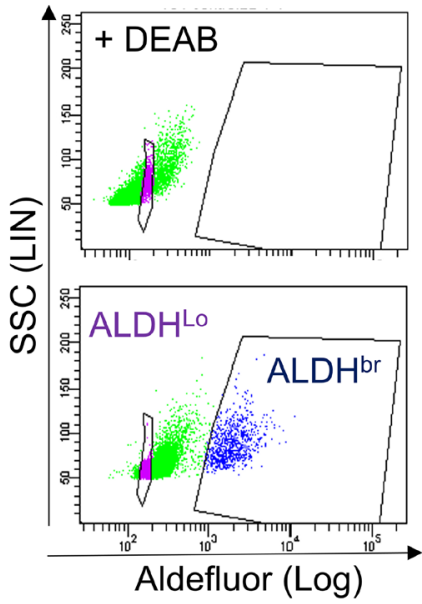

d

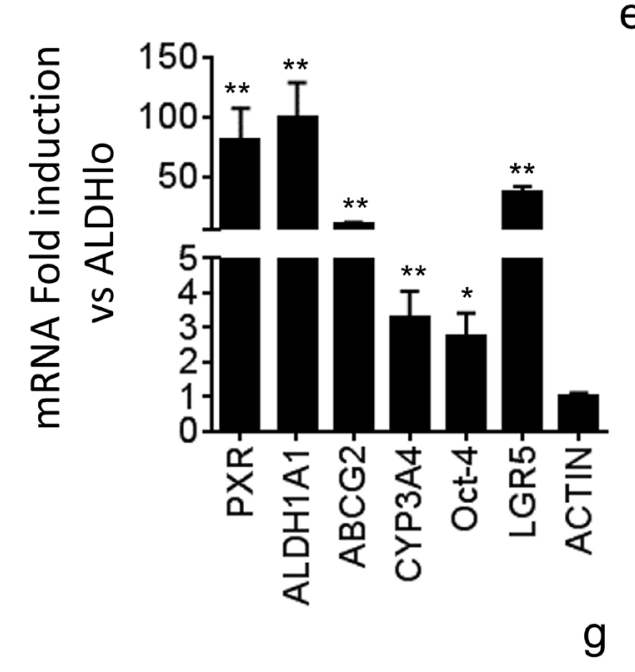

b

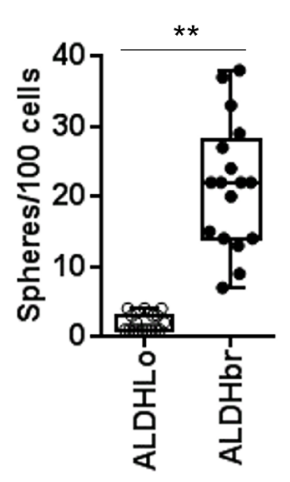

e

g

C
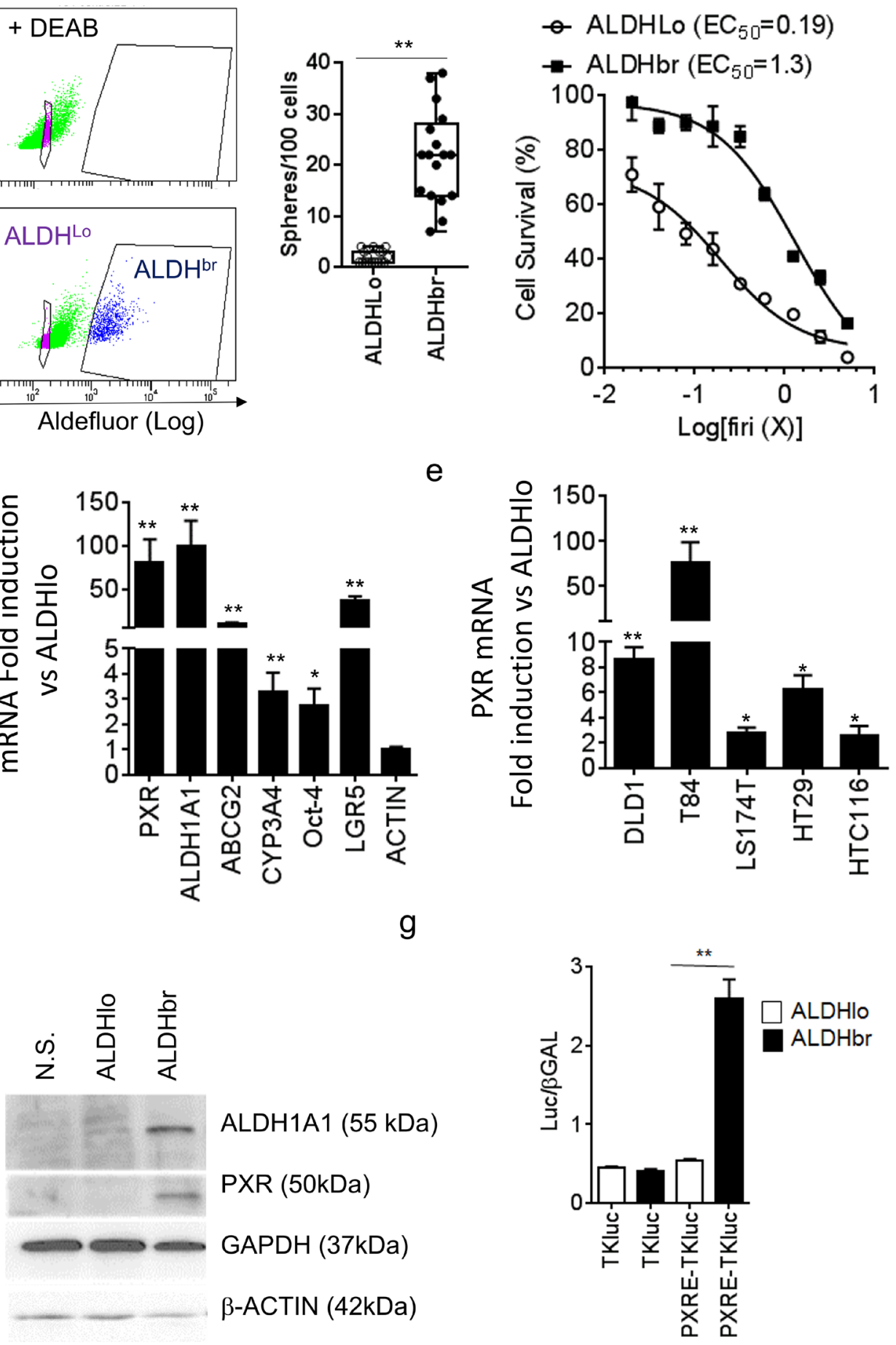

Figure 2: PXR expression is increased in colorectal ALDH ${ }^{\text {br }}$ CSCs. a. Aldefluor assay and gates used for CRC1 cell-sorting. The ALDH inhibitor DEAB was added to identify ALDH-positive (ALDH $\left.{ }^{\text {br }}\right)$ cells. b. Percentage of sphere-forming cells of the ALDH ${ }^{\text {br }}$ and $\mathrm{ALDH}^{\mathrm{lo}}$ populations. c. Percentage of surviving cells, 72 hours after exposure of $\mathrm{ALDH}^{\mathrm{br}}$ and $\mathrm{ALDH}^{\mathrm{lo}}$ cells to the indicated concentrations of Firi ( $1 \mathrm{X}=50 \mu \mathrm{M} 5$-FU $+500 \mathrm{nM} \mathrm{SN} 38)$. Data are expressed as mean \pm SEM of 3 experiments, and half maximal effective concentrations $\left(\mathrm{EC}_{50}\right)$ are indicated. d. RT-qPCR analyses of mRNA expression for PXR, PXR targets and CSC marker genes in the ALDH ${ }^{\mathrm{br}}$ compared to the $\mathrm{ALDH}^{\mathrm{lo}}$ population (F.I., Fold Induction). e. RT-qPCR quantification of PXR mRNA in ALDH ${ }^{\mathrm{br}}$ and $\mathrm{ALDH}^{\mathrm{lo}}$ cells from CRC cell lines. $d, e$ : Data are expressed as mean $\pm \mathrm{SEM}(\mathrm{n}=3)$ and reported as fold change compared to ALDH ${ }^{10}$ cells. f. ALDH1 A1, PXR, GAPDH and $\beta$-ACTIN protein expression in unsorted (NS), $\mathrm{ALDH}^{\mathrm{lo}}$ and $\mathrm{ALDH}^{\mathrm{br}} \mathrm{CRC1}$ cells. g. PXR transcriptional activity was determined in $\mathrm{ALDH}^{1 \mathrm{o}}$ and $\mathrm{ALDH}^{\mathrm{br}} \mathrm{CRC} 1$ cells 24 hours after transfection with luciferase reporter plasmids. Data are expressed as mean $\pm \mathrm{SEM}(\mathrm{n}=3)$ of luciferase/ $\beta$-Galactosidase ratio. *, $\mathrm{p}<0.05 ; * *, \mathrm{p}<0.005$. 
a

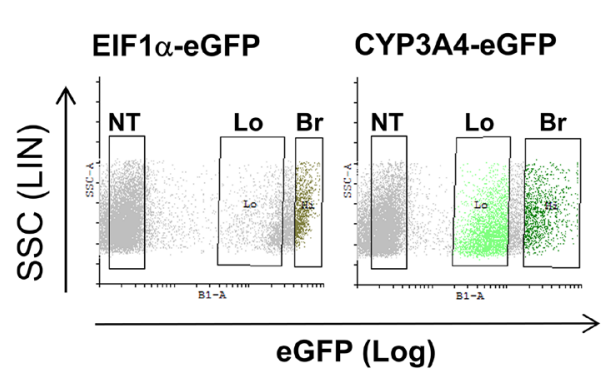

C

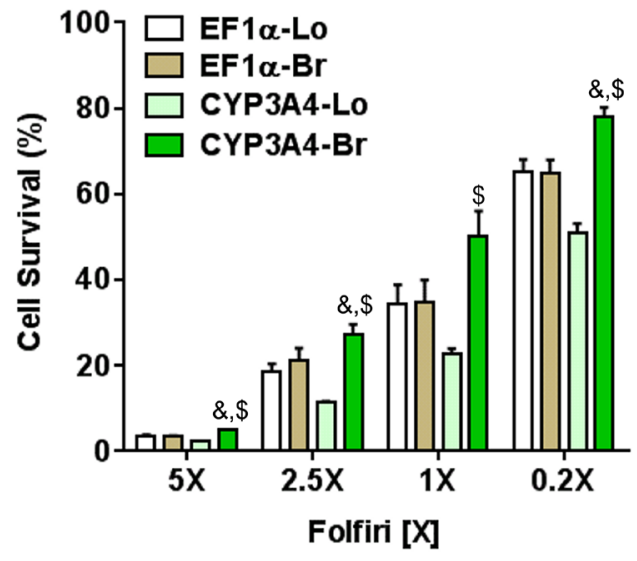

e

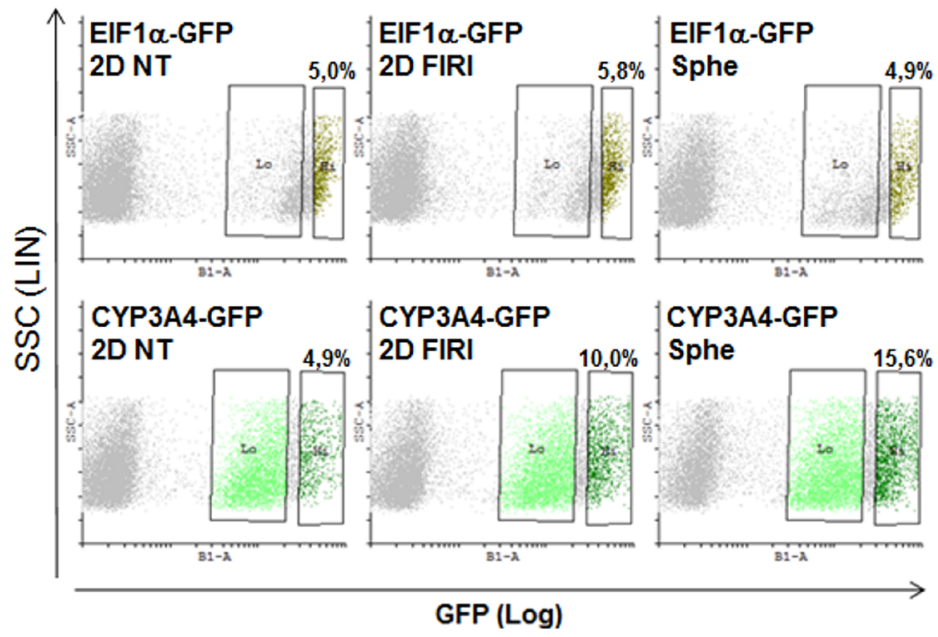

b
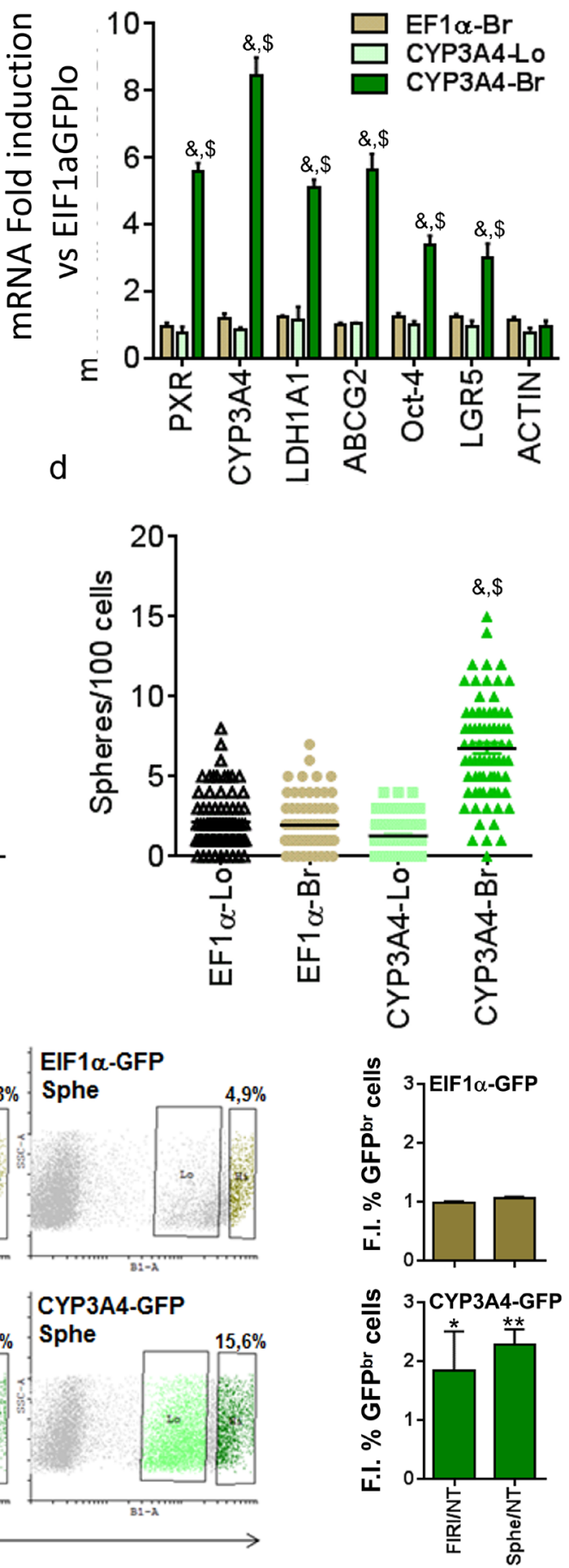

Figure 3: PXR transcriptional activity marks chemoresistant CSCs. a. Flow cytometry profiles of EIF1 $\alpha$-eGFP and CYP3A4eGFP infected T84 cells and regions used for cell-sorting. NT= Non infected, Lo=GFP low, Br=GFP bright. b. RT-qPCR analyses of PXR, PXR target and CSC marker gene mRNA expression in $B r$ and $L o$ populations compared to EIF1 $\alpha$-GFP low cells (F.I., Fold Induction). Data are expressed as mean \pm SEM $(n=3)$. c. Percentage of surviving cells, 72 hours after exposure of sorted cells to the indicated dilutions of Firi $(1 \mathrm{X}=50 \mu \mathrm{M} 5-\mathrm{FU}+500 \mathrm{nM} \mathrm{SN} 38)$. Data are expressed as mean $\pm \mathrm{SEM}(\mathrm{n}=4)$. d. Percentage of sphere-forming cells for $B r$ and $L o$ populations. a,b,c: \#: $\mathrm{p}<0.05$ compared to Lo cells for each GFP construct, $\$: \mathrm{p}<0.05$ compared to EIF1 $\alpha$-GFP Br cells. e. Representative flow cytometry profiles of EIF1 $\alpha$-eGFP- and CYP3A4-eGFP infected cells before (2D NT) or after 72h of Firi $(50 \mu \mathrm{M} 5$-FU $+500 \mathrm{nM}$ SN38) treatment followed by 2 days of recovery without treatment (2D FIRI) or maintained as colonospheres (Sphe). The fold increase in GFP $B r$ percentage induced by Firi (2D FIRI/2D NT) or colonosphere conditions (Sphe/2D NT) are indicated for each GFP construct as mean \pm SEM $(\mathrm{n}>3) .{ }^{*}, \mathrm{p}<0.05 ; * *, \mathrm{p}<0.005$. 
down regulation by shRNA (Figure 5c). Similar results were obtained in the T84 CRC cell line (Supplementary Figure S4c, S4d, S4e). Experiments using different shRNA sequences leading to the specific down-regulation of PXR expression or rescue experiment confirmed the

a

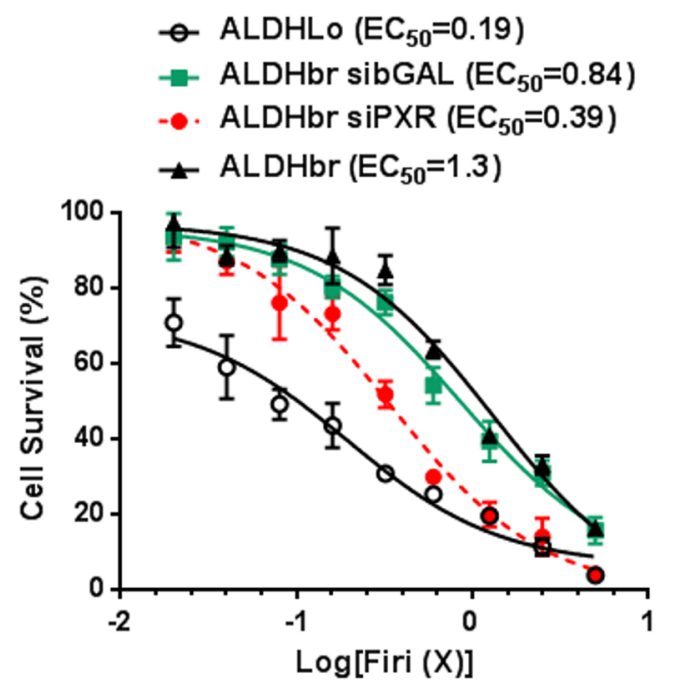

direct involvement of PXR on ALDH1A1 and Aldefluor activity level (Supplementary Figure S5). To assess the clinical relevance of correlation between PXR and ALDH expression, we compared PXR and ALDH1A1 mRNA expression in human samples. As shown, PXR

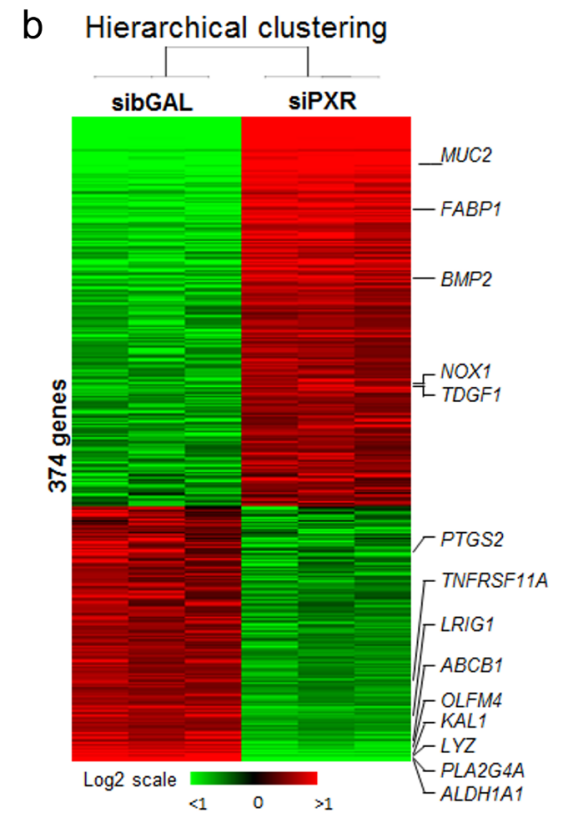

C

\begin{tabular}{l|cccc|cccc}
\hline & \multicolumn{4}{|c|}{ GES 374} & genes, up siPXR vs. sißGAL & \multicolumn{3}{c}{ GES 374 genes, down siPXR vs. sißGAL } \\
& N.GeneSet & N.GES & p.value* & q.value** & N.GeneSet & N.GES & p.value & q.value ${ }^{* *}$ \\
\hline Oh et al. POOR PROGNOSIS & 52 & $\leq 1$ & NA & NA & 52 & 3 & $9.40 E-05$ & $1.88 E-04$ \\
Oh et al. GOOD PROGNOSIS & 32 & 3 & $5.67 E-05$ & $1.13 E-04$ & 32 & $\leq 1$ & NA & NA \\
\hline
\end{tabular}

*Hypergeometric test of gene set enrichment

** FDR adjustement

d
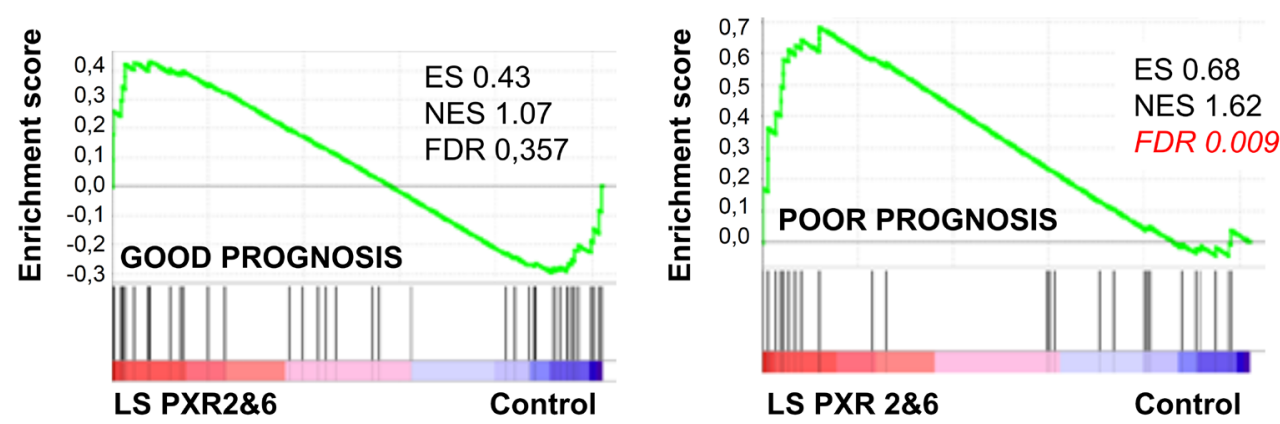

Figure 4: PXR regulates a large network of key CSC chemoresistance genes. a. Percentage of surviving cells, 48 hours after exposure of cells to the indicated concentrations of Firi $(1 \mathrm{X}=50 \mu \mathrm{M} 5-\mathrm{FU}+500 \mathrm{nM} \mathrm{SN38})$. ALDH ${ }^{\text {br }} \mathrm{CRC} 1$ cells were first transfected with or without $100 \mathrm{nM}$ of control (si GGA) or PXR-specific (siPXR-1334) siRNA. Data are expressed as mean \pm SEM (n=3). b. Hierarchical clustering of 6 samples and 374 genes, differentially expressed between PXR siRNA (siPXR) and control sißGAL-transfected ALDH ${ }^{\text {br }}$ $\mathrm{CRC1}$ cells. Each row represents a gene and each column represents a sample. c,d. Gene set enrichment analyses (GSEA) were used to interrogate the similarity of genes that were differentially expressed in the microarray experiments after loss- (c) or gain-of PXR (d) function, to signatures of patient prognosis (Oh, S.C., et al. Gut 61, 1291-1298 (2012)). c: genes induced by siRNA-mediated PXR depletion in ALDHbr cells "Up siPXR vs. sißGAL" or decreased by PXR depletion "Down siPXR vs. sißGAL". $d$ : PXR-overexpressing LS174T clones $2 \& 6$ versus LS174T control. 

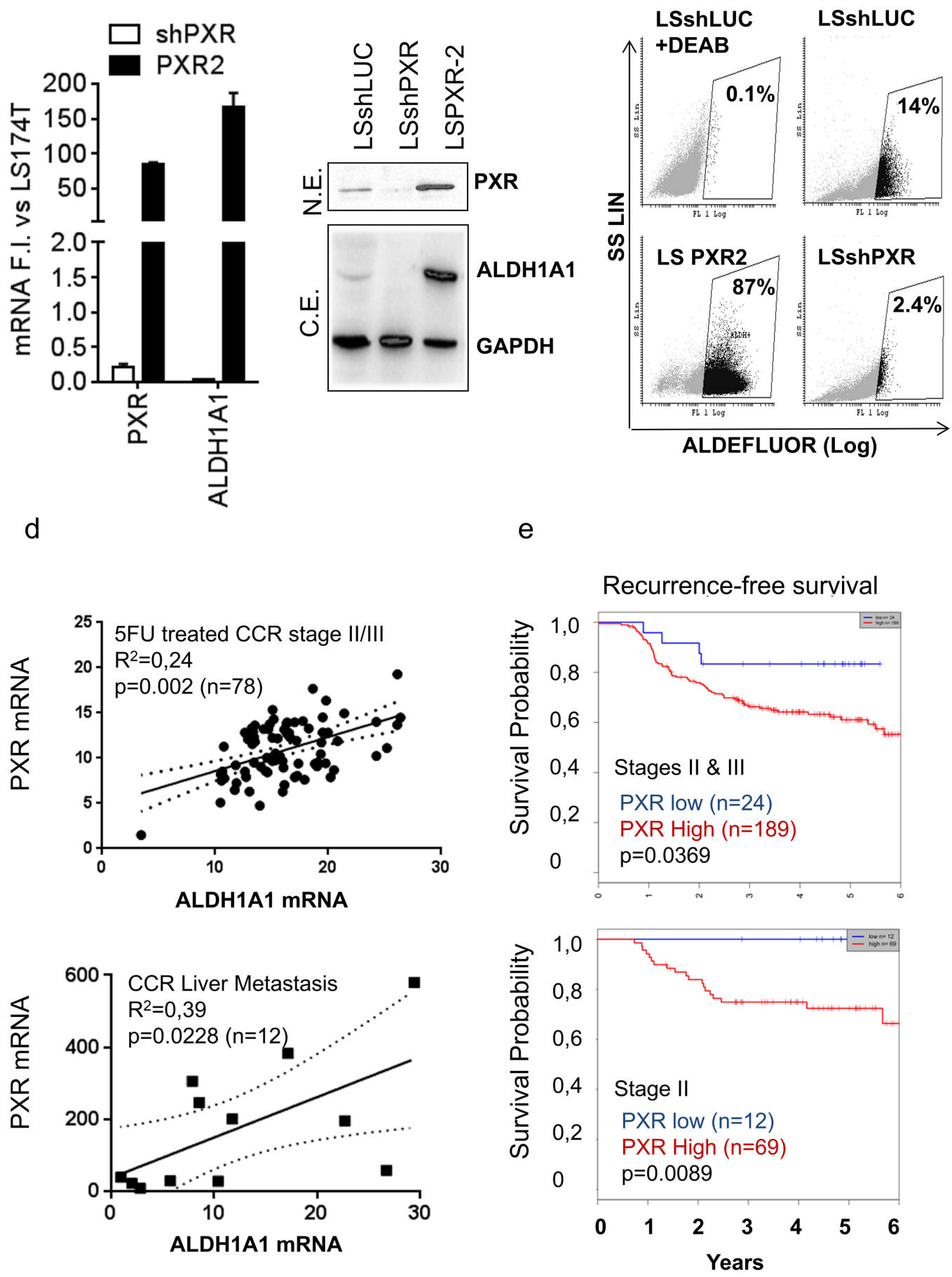

Figure 5: PXR mRNA expression correlates with ALDH1A1 expression and is a poor prognosis factor in colon cancer patients. a. RT-qPCR analyses of PXR and ALDH1A1 mRNA expression, b. detection of PXR, ALDH1A1 and GAPDH protein expression by Western blotting after loss- (shPXR) or gain of PXR expression (PXR2). $a$ : Data are expressed as mean $\pm \mathrm{SEM}$ ( $\mathrm{n} \geq 3$ ) compared to LS174T control cells (shLUC) (F.I., Fold Induction). $b$ : N.E. $=$ nuclear extracts, C.E. $=$ cytosolic extracts. c. Quantification of ALDH activity using the Aldefluor assay. Percentages of $\mathrm{ALDH}^{\text {br }}$ cells are indicated in inset boxes. d. Correlation between PXR and ALDH1A1 mRNA expression in CRC primary tumors of stage II or III patients treated with 5-FU-based chemotherapy ( $\mathrm{n}=78$ ) or in human liver metastasis samples $(\mathrm{n}=12)$ obtained from patients with metastatic colorectal disease. e. Kaplan-Meier estimates of the probability of resting free from tumor recurrence, according to PXR expression level in CRC primary tumors of stage II \& III (upper panel), or stage II (lower panel) patients treated with 5-FU-based chemotherapy. PXR expression was normalized according to RPLO mRNA expression. Patients with low PXR gene expression are depicted in blue and patients with high PXR gene expression in red. $p$ value from the likelihood ratio test is shown in each case. 
and ALDH1A1 were significantly correlated in primary tumor samples from stage II \& III CCR patients $(\mathrm{n}=78)$ and in CRC liver metastatic samples $(\mathrm{n}=12)$ (Figure 5d). In addition, we attempted to determine whether PXR expression was correlated with clinical outcome in homogenous groups of chemotherapy-treated colorectal cancer patients. We first performed a Kaplan-Meier analysis of PXR mRNA expression in 5-FU-treated stage II/III CRC patient cohort [37]. We found that patients bearing tumors with high PXR expression had a significantly lower probability of disease-free survival, indicating that high PXR is associated with poor prognosis in stage II/III colon cancer patients treated with $5-\mathrm{FU}$ based chemotherapy $(n=213 ; p=0.0369$; Figure 5e). This effect was even more markedly increased when we analysed the outcome for stage II patients only $(n=81$; $\mathrm{p}=0.0089$ ), for whom finding biomarkers of treatment outcome is an urgent clinical need. Similar results were obtained by using RPLO (Figure 5e) or GAPDH (Supplementary Figure S6) as reference gene. These results clearly demonstrated that elevated PXR expression in CCR patients is positively correlated with a higher recurrence frequency, an outcome that is often driven by the persistence of chemoresistant cancer stem cells.

\section{PXR knockdown increases recurrence-free survival in mouse xenograft models}

To study the relationship between PXR and CSCs chemoresistance, we established spheroid cultures from patient-derived colorectal tumor samples (CRC1) and infected these cells with a lentivirus allowing the stable expression of small hairpin RNAs targeted against PXR (shPXR) or a control (shLUC). A significant downregulation of PXR and PXR-regulated gene mRNAs was observed in shPXR-expressing spheroids (Figure 6a). PXR depletion reduced both the ALDH ${ }^{\text {br }}$ cell population (Supplementary Figure S7) and sphere-forming potential (Figure 6b) and these effects were strongly amplified following serial spheroid passaging. To determine the impact of PXR on CSC chemoresistance and posttreatment relapse, we generated tumor xenografts by subcutaneously injecting 15,000 PXR-deficient (shPXR) or control (shLUC) cells from spheroids into nude mice ( $\mathrm{n}=18$ /group). Twenty days after injection, mice were randomized and received either vehicle or a Folfiri regimen $(90 \mathrm{mg} / \mathrm{kg}$ leucovorin, $50 \mathrm{mg} / \mathrm{kg} 5-\mathrm{FU}$ and $30 \mathrm{mg} /$ $\mathrm{kg}$ irinotecan, twice a week from day 23 to 45) designed to induce tumor regression [39]. Tumor growth was noticeably slower in shPXR group compared to shLUC control group in absence of treatment and tumor stasis upon Folfiri treatment was detected in both groups (Figure 6c). Three days after treatment cessation (day 48), six mice from the vehicle- and Folfiri-treated groups were sacrificed for subsequent analysis, while tumor growth and post-treatment relapse were monitored in the remaining mice. Recurrence was clearly noticeable from 3 weeks post-treatment (day 69) in shLUC control group, which had a $\approx 2$-fold accelerated growth rate compared to untreated tumors. In contrast, the growth rate of shPXR tumors did not increase after Folfiri treatment (Figure 6c) and their recurrence was strongly delayed (Log-Rank Mantel-Cox test $\mathrm{p}=0.029$; Figure $6 \mathrm{~d}$ ). Thus PXR depletion efficiently prolongs progression-free survival following chemotherapy. Finally, to determine whether PXR downregulation affected the in vivo tumor-initiating potential of Folfiri-resistant tumor cells, we subcutaneously transplanted 1,500 cells obtained from residual tumors collected three days after treatment completion (day 48 ) into new nude mice (Figure 6e). Cells isolated from Folfiri-treated shLuc control tumors induced the rapid formation of second-generation tumors in all grafted animals. In contrast, tumor growth rate was much lower in mice injected with cells isolated from Folfiri-treated shPXR tumors and tumor incidence was strongly delayed (Log Rank Mantel-Cox test $p=0.026$; Figure 6f). These results clearly indicate that shRNA silencing of PXR delays tumor relapse and affects in vivo tumor-initiating potential of CRC cells following chemotherapy.

\section{PXR depletion impairs chemotherapy-induced enrichment of tumorigenic CSCs in vivo}

To understand the cellular mechanism involved in the tumor relapse of CRC cells following chemotherapy, we analyzed the reservoir of CSCs from tumors, collected three days after treatment cessation (Figure 6c, day 48). We first analyzed the frequency of CSCs from tumors collected at day 48 from untreated and folfiri-treated mice. In agreement with the literature [8], we found a significant increase of spheroid-forming efficiency after Folfiri treatment in control tumors (Figure 7a), suggesting that chemotherapy increased the proportion of CSCs whilst eliminating the more differentiated and proliferative tumor cells. However, this selection of CSCs was completely abolished in shPXR-derived tumors. Indeed, spheroid-forming efficiency was even lower in shPXR-derived tumors cells following chemotherapy compared to untreated shPXR or shLUC tumor cells, therefore the down-regulation of PXR completely prevents chemotherapy-induced CSC enrichment. Accordingly, while the proportion of $\mathrm{ALDH}^{\mathrm{br}}$ cells was significantly increased in Folfiri-treated control tumors, this enrichment was completely impaired in tumors derived from Folfiri-treated shPXR group (Figure 7b). Moreover, ALDH1A1-positive cells were barely detectable by immunohistochemistry in sections of Folfiri-treated tumor xenografts in the shPXR group compared to control group (Figure 7c). In addition, RT-qPCR revealed a large increase of PXR and CSC gene marker (ALDH1A1, Oct4 and LGR5) mRNA expression after Folfiri treatment of control tumors (Figure 7d). These increases were severely 
impaired in shPXR tumors. Comparable results were obtained in vitro in patient-derived cells (CRC1) or in the LS174T cell line (Supplementary Figure S8) treated with a combination of $5 \mathrm{FU}$ and SN38. These results suggest that PXR signaling plays an instrumental role in CSC resistance and that PXR inhibition minimizes the clinically problematic enrichment of these cells in response to chemotherapy.

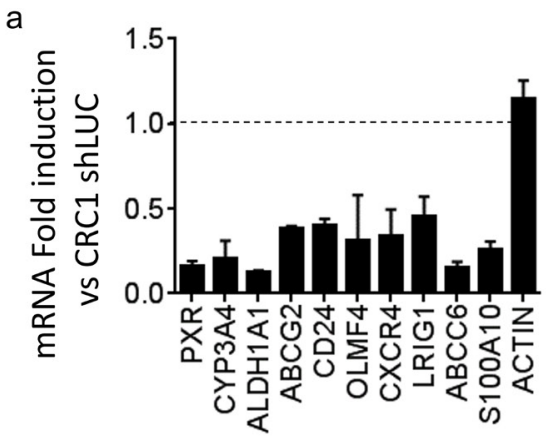

C b

d
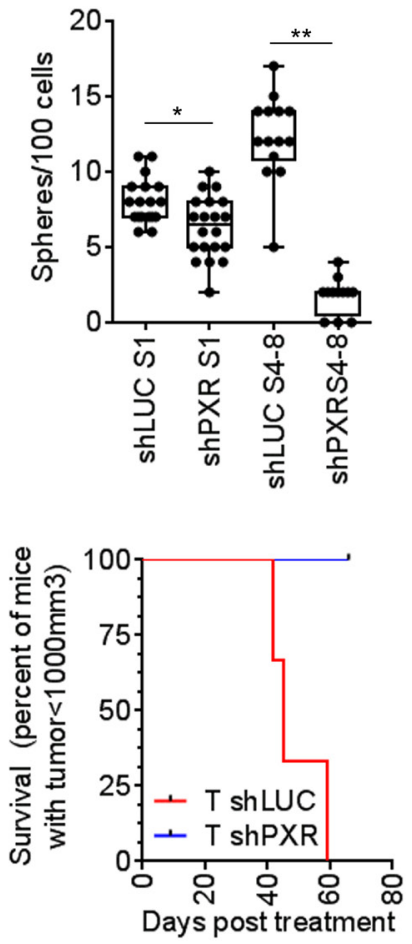

f

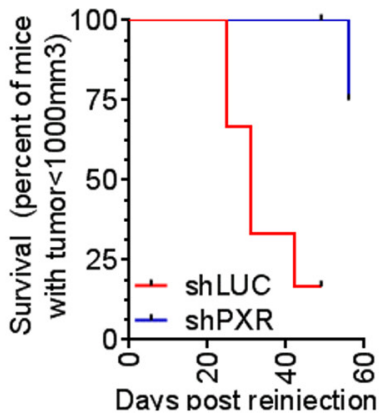

Figure 6: Knock-down of PXR decreases CSC-self renewal and improves recurrence free survival in mouse xenograft models. a. RT-qPCR analyses of PXR and PXR target gene mRNA expression in CRC1 cells expressing PXR-shRNA (shPXR-1334). Data are expressed as mean \pm SEM $(\mathrm{n}=3)$ compared to control CRC1 cells (CRC1 shLUC). ${ }^{*}, \mathrm{p}<0.05 ; * *, \mathrm{p}<0.005$. b. Percentage of sphere-forming cells of shLuc and shPXR CRC1 colon cancer cells maintained as first-generation spheres (S1) or after 4-8 passages (S4$\mathrm{S} 8)$. Data are expressed as mean $\pm \mathrm{SEM}(\mathrm{n}=3)$. c. Tumor volume over time after subcutaneous injection of 15,000 shLuc or shPXR CRC1 colon cancer cells isolated from colonospheres (18mice/group). Mice were randomized once tumors reached a volume of $100 \mathrm{~mm}^{3}$ (day 20). Three days after randomization, one group (6 mice/group) was treated twice weekly for 4 weeks with vehicle or with Folfiri. At day 48 , three days after the end of treatment, 6 mice per group were sacrificed and the remaining ones from the Folfiri-treated groups (6 mice/ group) were kept for 7 weeks without treatment to further monitor tumor growth. Data are expressed as mean \pm SEM of the fold-increase (F.I.) compared to the corresponding tumor volume at day 20. d. Kaplan-Meier survival plots after treatment cessation representing the time for animals to reach the endpoint tumor size of $1000 \mathrm{~mm} 3$. e. Tumor volume over time after subcutaneous injection of tumor cells obtained at day 48 from xenograft tumors shown in (c), processed for cell dissociation and sub-cutaneously re-implantated in immunodeficient mice (6 mice/group, 1,500 live (7-AAD-negative) cells/mouse). f. Survival plots after secondary injection of residual Folfiri-treated shLUC or shPXR cells. 


\section{DISCUSSION}

PXR is a nuclear receptor whose downstream target genes are involved in the production of phase I and II metabolic enzymes and phase III drug transporters. PXR activation has been implicated in poor response of cancer cells [40]. Here we show that the activity of this receptor is largely restricted to the minority self-renewing cellsubpopulation of tumors and that it is responsible for the ability of cancer stem cells to successfully withstand sustained chemotoxic aggression and this drives posttreatment tumor recurrence. First, we observed that PXR

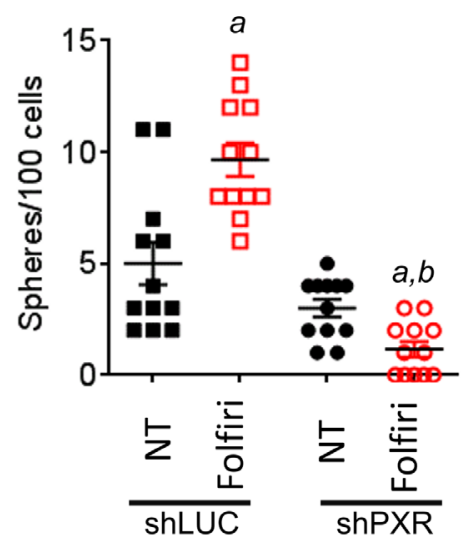

C
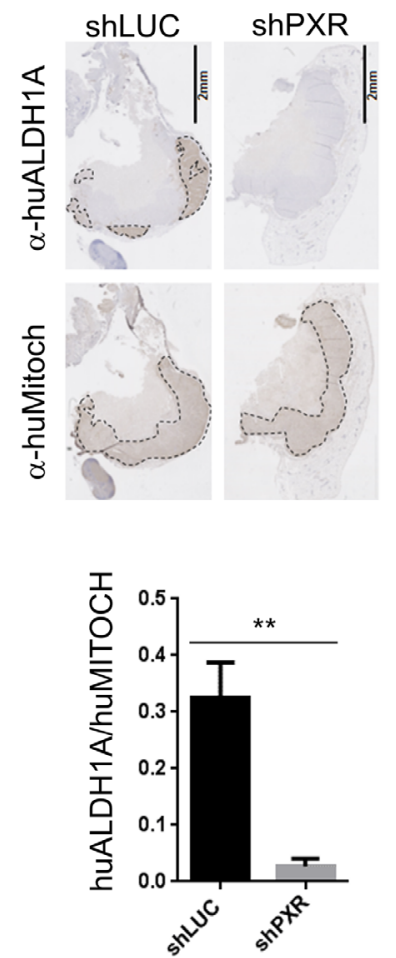

d
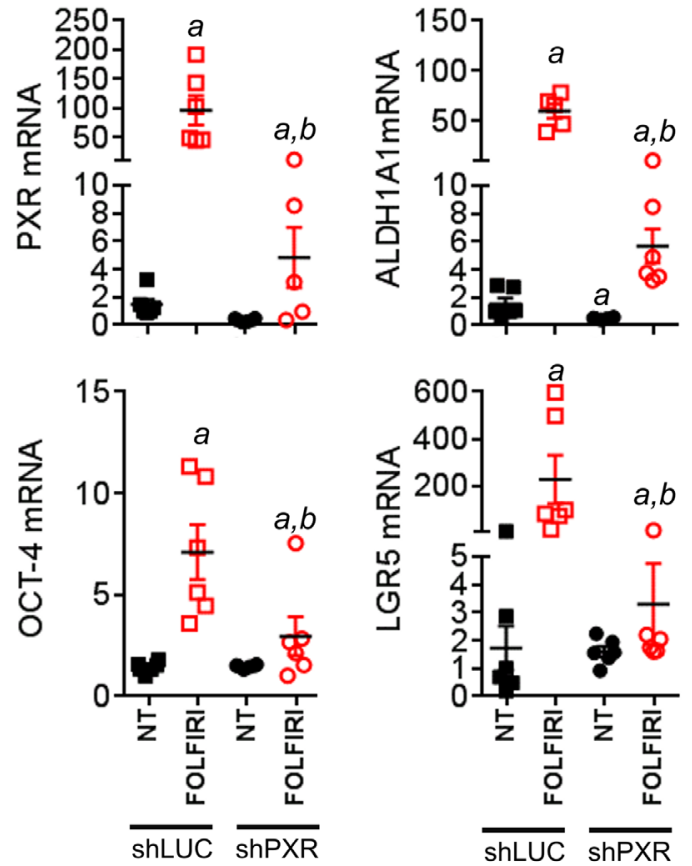

Figure 7: PXR depletion impairs chemotherapy-induced enrichment of PXR and CSC markers in vivo. Tumor samples from mice sacrificed at day 48 (see Figure 6c) were processed for cell dissociation and, live (7-AAD-negative) tumor cells were further analyzed for their a. ability to initiate sphere formation in vitro and b. Aldefluor activity (\% of ALDH ${ }^{\text {br }}$ cells). Data are expressed as mean \pm SEM. " $a$ ", $\mathrm{p}<0.05$ compared to non-treated shLUC tumors and " $b$ ", $\mathrm{p}<0.05$ compared to Folfiri-treated shLuc tumors. c. Hematoxylin/Eosin and immunostaining of Folfiri-treated shLuc and shPXR paraffin-embedded tumor sections (day 48) using antibodies directed against human ALDH1A ( $\alpha$-huALDH1 A, detecting ALDH1A1 protein [54-56]) or human mitochondria ( $\alpha$-huMitoch). Ratios of ALDH1A/human mitochondria-stained areas on tumor sections ( $\mathrm{n}=4$ /group) are presented below. Data are expressed as mean \pm SEM. **, $\mathrm{p}<0.005 \mathrm{~d}$. Expression of the indicated mRNAs was quantified by RT-qPCR on cells isolated from dissociated tumors (day 48) of nontreated or Folfiri-treated mice. Data are expressed as mean \pm SEM. "a", $\mathrm{p}<0.05$ compared to non-treated shLUC tumors and " $b$ ", $\mathrm{p}<0.05$ compared to Folfiri-treated shLuc tumors. 
expression is higher in CSC-enriched tumor cells. PXR expression was enriched during spheroid passaging (Figures 1 and Supplementary Figure S1), after cell sorting using Aldefluor activity (Figures 2 and Supplementary Figure S2) and also after drug selection in several CCR cell lines and patient-derived cells (Figures 7, Supplementary Figure S8, S9 and S10). In addition, CRC cells with enhanced PXR transcriptional activity had increased expression of CSC markers, self-renewal and chemoresistance (Figure 3). These results are in agreement with the fact that, PXR was one of the most overexpressed nuclear receptors in human glioma stem cells compared to glioma cells [41].

By using both gain- and loss- of function approaches, we show that PXR drives the expression of a large number of genes that promote several hallmarks of cancer stem cells, such as chemoresistance, DNA repair and selfrenewal (Supplementary Tables S2 and S3). Notably, we observed that PXR controls the expression of genes that were previously reported to confer CSC chemoresistance or to have a negative impact on disease-free survival in colon cancer patients, including ABCG2, ABCC6, ALDH1A1, CYP3A4, or S100A10. These observations were corroborated by our observation that stage II and III CRC patients with high PXR expression have a lower probability of disease-free survival after chemotherapy
(Figures 5 and Supplementary Figure S6), while GSEA analyses showed that PXR target genes are associated with a poor-prognosis molecular signature in colorectal cancer patients (Figure 4). These data strongly suggest that PXR is an upstream molecular switch in CSCs that drives a network of key downstream targets that enable them to resist treatment. PXR may promote the adaptation of CSCs to their environment by providing them with a multi-faceted arsenal that includes an enhanced capacity to resist cell death and chemotoxic insult and thus the ability to selfrenew and maintain their stemness potential.

We demonstrate that PXR down-regulation decreased CSCs chemoresistance (Figure 4a) and chemotherapy-induced CSC enrichment and it also significantly delayed tumor relapse after Folfiri treatment of xenografted animals (Figure 6). In addition, the tumor-initiating ability of residual tumor cells and the proportion of CSCs found in tumor xenografts at the end of Folfiri treatment were strongly decreased in PXR knockdowns (Figure 6). These observations imply that PXR may represent a key target to improve the efficiency of conventional chemotherapy through the sensitization of CSCs and counteract the selection/emergence of chemoresistant CSCs (Figure 8). The potential implications of these results are far-reaching as post-

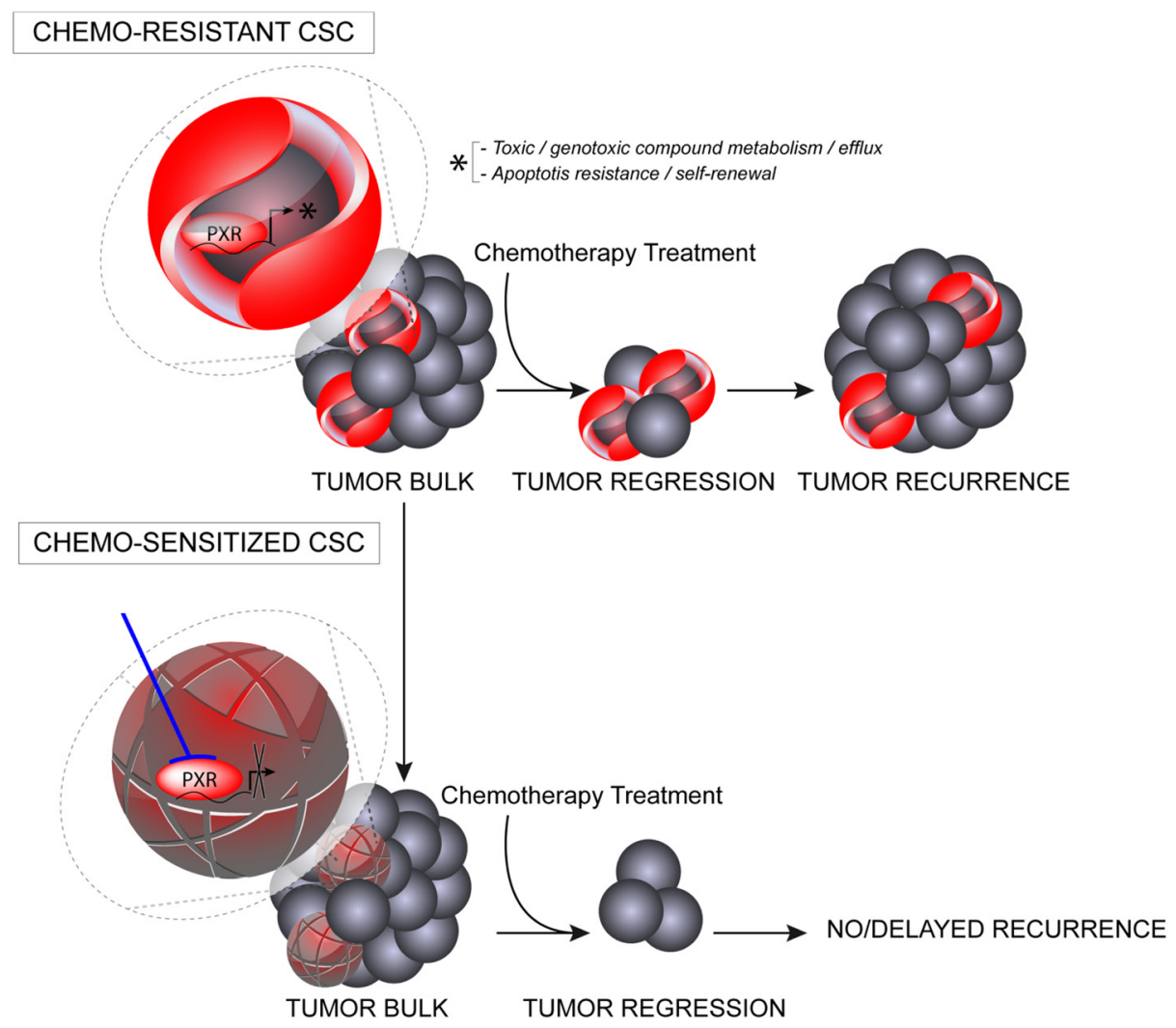

Figure 8: Schematic representation of putative PXR roles in CSC survival and tumor recurrence. PXR expression in CSCs leads to enhanced transcription of PXR target genes promoting CSC plasticity by providing these cells with a defense arsenal that includes drug-metabolizing and transporter genes, enhanced capacity to deal with oxidative stress and genome alterations, and enhanced anti-apoptotic capabilities. Targeting PXR expression/activity using pharmacological inhibitors, may down regulate this multi-faceted protection against cytotoxic drugs and improve the efficiency of conventional chemotherapy in CRC patients through the sensitization of CSCs. 
treatment relapse is one of the major issues hampering clinical managements of CRC.

The large network of genes controlled by PXR in CSCs suggests that this receptor is a potential Achilles' heel for CSCs in colorectal cancers. Additionally, this may be true for other human cancers, as significant PXR expression levels have been detected in prostate, breast and ovarian cancers, where Aldefluor activity and ALDH1A1 expression are enriched in chemo-resistant CSCs [42-44]. Interestingly ALDH1A1 was among the most significantly deregulated genes after PXR knockdown or gain of function. Despite accumulating evidence in several cancers for the functional role of ALDH1A1 enzyme in CSC self-renewal and survival [45], the specific mechanisms involved in its regulation in CSCs remain unclear. Here we observed that PXR is an important driver of ALDH1A1 expression and activity in human colon CSC cells (Figures 5, Supplementary Figures S4 and S5). These results are in agreement with previous studies showing that Pxr activation increases both Aldh1a1 mRNA expression [20] and Pxr binding to the Aldhlal gene [46] in mouse liver.

Finally, along with reports documenting the tumorpromoting [47] and chemoresistance properties [48] of PXR, and considering that Pxr knockout mice are viable, fertile and do not display major defects [49], our data point to PXR as a promising target to improve the efficiency of conventional chemotherapy. Interestingly, two molecules that were recently reported to interact synergistically with chemotherapies to eliminate CSCs, L-sulphoraphane and metformin $[3,50,51]$, are non-selective PXR inhibitors $[52,53]$. Thus, development of selective PXR-signaling inhibitors will represent an important step towards the validation of PXR as a clinically druggable target in comparison with these multi-targeted compounds.

\section{ACKNOWLEDGMENTS}

We thank P. Crespy for his technical expertise and lab management, C. Duperray (IRBM, Montpellier) and M. Boyer (IGMM, Montpellier) from the Montpellier RIO Imaging platform for flow cytometry experiments, and M. Asari for her help in figure design. This work was supported by Grants from the Labex EpiGenMed and Université de Montpellier (F.R), Association pour la Recherche contre le Cancer (\#16922 and SFI20121205749), Ligue régionale contre le cancer (Hérault, 6F11728PMBZ), the National Health and Medical Research Council of Australia (\#\#1049561) and from Fundación Científica de la Asociación Española contra el Cáncer (GCB13131592CAST).

\section{CONFLICTS OF INTEREST}

Authors have nothing to disclose.

\section{Author contributions}

F.H, J.P and JM.P designed the research; C.P and F.H, J.P and JM.P designed part of the experiments, C.P, F.R, F.G, P.F, B.B, J.G, V.G, C.V, DV.B, L.C, J.K, A.P and JMP performed the experiments; C.P, F.B, M.G, C.G, F.H, J.P and JM.P analyzed the data; M.P, J.R, JF.B, M.G, A.C, JFB provided reagents/analytic tools; CP, FH, JP and JMP wrote the manuscript.

\section{REFERENCES}

1. Alwan A. World Health Organization. Disaster Med Public Health Prep. 2007; 1: 7-8. doi: 10.1097/DMP. 0b013e3180676d32 01273293-200707000-00008.

2. Chau I, Cunningham D. Treatment in advanced colorectal cancer: what, when and how? Br J Cancer. 2009; 100: 170419. doi: 6605061 [pii] 10.1038/sj.bjc.6605061.

3. Prud'homme GJ. Cancer stem cells and novel targets for antitumor strategies. Curr Pharm Des. 2012; 18: 2838-49. doi: CPD-EPUB-20120228-014.

4. Dalerba P, Dylla SJ, Park IK, Liu R, Wang X, Cho RW, Hoey T, Gurney A, Huang EH, Simeone DM, Shelton AA, Parmiani G, Castelli C, et al. Phenotypic characterization of human colorectal cancer stem cells. Proc Natl Acad Sci U S A. 2007; 104: 10158-63. doi: 0703478104 [pii] 10.1073/ pnas. 0703478104.

5. Ricci-Vitiani L, Lombardi DG, Pilozzi E, Biffoni M, Todaro M, Peschle C, De Maria R. Identification and expansion of human colon-cancer-initiating cells. Nature. 2007; 445: 111-5. doi: 10.1038/nature05384.

6. Kreso A, O'Brien CA, van Galen P, Gan OI, Notta F, Brown AM, Ng K, Ma J, Wienholds E, Dunant C, Pollett A, Gallinger S, McPherson J, et al. Variable clonal repopulation dynamics influence chemotherapy response in colorectal cancer. Science. 2013; 339: 543-8. doi: 10.1126/ science. 1227670.

7. Todaro M, Alea MP, Di Stefano AB, Cammareri P, Vermeulen L, Iovino F, Tripodo C, Russo A, Gulotta G, Medema JP, Stassi G. Colon cancer stem cells dictate tumor growth and resist cell death by production of interleukin-4. Cell Stem Cell. 2007; 1: 389-402. doi: S19345909(07)00118-X [pii] 10.1016/j.stem.2007.08.001.

8. Dylla SJ, Beviglia L, Park IK, Chartier C, Raval J, Ngan L, Pickell K, Aguilar J, Lazetic S, Smith-Berdan S, Clarke MF, Hoey T, Lewicki J, et al. Colorectal cancer stem cells are enriched in xenogeneic tumors following chemotherapy. PLoS One. 2008; 3: e2428.

9. Merlos-Suarez A, Barriga FM, Jung P, Iglesias M, Cespedes MV, Rossell D, Sevillano M, Hernando-Momblona X, da Silva-Diz V, Munoz P, Clevers H, Sancho E, Mangues R, et al. The intestinal stem cell signature identifies colorectal cancer stem cells and predicts disease relapse. Cell Stem 
Cell. 2011; 8: 511-24. doi: S1934-5909(11)00110-X [pii] 10.1016/j.stem.2011.02.020.

10. Hollande F, Pannequin J, Joubert D. The long road to colorectal cancer therapy: searching for the right signals. Drug Resist Updat. 2010; 13: 44-56. doi: 10.1016/j. drup.2009.01.002.

11. Haraguchi N, Utsunomiya T, Inoue H, Tanaka F, Mimori K, Barnard GF, Mori M. Characterization of a side population of cancer cells from human gastrointestinal system. Stem Cells. 2006; 24: 506-13. doi: 2005-0282 [pii] 10.1634/ stemcells.2005-0282.

12. Huang EH, Hynes MJ, Zhang T, Ginestier C, Dontu G, Appelman H, Fields JZ, Wicha MS, Boman BM. Aldehyde dehydrogenase 1 is a marker for normal and malignant human colonic stem cells (SC) and tracks SC overpopulation during colon tumorigenesis. Cancer Res. 2009; 69: 3382-9.

13. Olszewski U, Liedauer R, Ausch C, Thalhammer T, Hamilton G. Overexpression of CYP3A4 in a COLO 205 Colon Cancer Stem Cell Model in vitro. Cancers (Basel). 2011; 3: 1467-79. doi: 10.3390/cancers3011467.

14. Achuthan S, Santhoshkumar TR, Prabhakar J, Nair SA, Pillai MR. Drug-induced senescence generates chemoresistant stemlike cells with low reactive oxygen species. J Biol Chem. 2011; 286: 37813-29. doi: M110.200675 [pii] 10.1074/jbc.M110.200675.

15. Shenoy A, Butterworth E, Huang EH. ALDH as a marker for enriching tumorigenic human colonic stem cells. Methods Mol Biol. 2012; 916: 373-85. doi: 10.1007/978-1-61779-980-8_27.

16. Chikazawa N, Tanaka H, Tasaka T, Nakamura M, Tanaka M, Onishi H, Katano M. Inhibition of Wnt signaling pathway decreases chemotherapy-resistant side-population colon cancer cells. Anticancer Res. 2010; 30: 2041-8.

17. Sladek NE, Kollander R, Sreerama L, Kiang DT. Cellular levels of aldehyde dehydrogenases (ALDH1A1 and ALDH3A1) as predictors of therapeutic responses to cyclophosphamide-based chemotherapy of breast cancer: a retrospective study. Rational individualization of oxazaphosphorine-based cancer chemotherapeutic regimens. Cancer Chemother Pharmacol. 2002; 49: 309-21. doi: 10.1007/s00280-001-0412-4.

18. Lehmann JM, McKee DD, Watson MA, Willson TM, Moore JT, Kliewer SA. The human orphan nuclear receptor PXR is activated by compounds that regulate CYP3A4 gene expression and cause drug interactions. J Clin Invest. 1998; 102: 1016-23.

19. Raynal C, Pascussi JM, Leguelinel G, Breuker C, Kantar J, Lallemant B, Poujol S, Bonnans C, Joubert D, Hollande F, Lumbroso S, Brouillet JP, Evrard A. Pregnane X Receptor (PXR) expression in colorectal cancer cells restricts irinotecan chemosensitivity through enhanced $\mathrm{SN}-38$ glucuronidation. Mol Cancer. 2010; 9: 46.
20. Alnouti Y, Klaassen CD. Tissue distribution, ontogeny, and regulation of aldehyde dehydrogenase (Aldh) enzymes mRNA by prototypical microsomal enzyme inducers in mice. Toxicol Sci. 2008; 101: 51-64. doi: kfm280 [pii] 10.1093/toxsci/kfm280.

21. Lemmen J, Tozakidis IE, Galla HJ. Pregnane X receptor upregulates $\mathrm{ABC}$-transporter $\mathrm{Abcg} 2$ and $\mathrm{Abcb} 1$ at the blood-brain barrier. Brain Res. 2013; 1491: 1-13. doi: 10.1016/j.brainres.2012.10.060.

22. Saigusa S, Tanaka K, Toiyama Y, Yokoe T, Okugawa Y, Ioue Y, Miki C, Kusunoki M. Correlation of CD133, OCT4, and SOX2 in rectal cancer and their association with distant recurrence after chemoradiotherapy. Ann Surg Oncol. 2009; 16: 3488-98. doi: 10.1245/s10434-009-0617-z.

23. Deng $\mathrm{Y}, \mathrm{Su} \mathrm{Q}, \mathrm{Mo} \mathrm{J}, \mathrm{Fu} \mathrm{X}$, Zhang $\mathrm{Y}$, Lin EH. Celecoxib Downregulates CD133 Expression Through Inhibition of the Wnt Signaling Pathway in Colon Cancer Cells. Cancer Invest. 2012; 31: 97-102. doi: 10.3109/07357907.2012.754458.

24. Drocourt L, Ourlin JC, Pascussi JM, Maurel P, Vilarem MJ. Expression of CYP3A4, CYP2B6, and CYP2C9 is regulated by the vitamin $\mathrm{D}$ receptor pathway in primary human hepatocytes. J Biol Chem. 2002; 277: 25125-32. doi: 10.1074/jbc.M201323200.

25. Emmink BL, Verheem A, Van Houdt WJ, Steller EJ, Govaert KM, Pham TV, Piersma SR, Borel Rinkes IH, Jimenez CR, Kranenburg O. The Secretome of Colon Cancer Stem Cells Contains Drug-metabolizing Enzymes. J Proteomics. 2013. doi: S1874-3919(13)00373-4 [pii] 10.1016/j.jprot.2013.06.027.

26. Duong HQ, Hwang JS, Kim HJ, Kang HJ, Seong YS, Bae I. Aldehyde dehydrogenase $1 \mathrm{~A} 1$ confers intrinsic and acquired resistance to gemcitabine in human pancreatic adenocarcinoma MIA PaCa-2 cells. Int J Oncol. 2012; 41: 855-61. doi: 10.3892/ijo.2012.1516.

27. Schafer A, Teufel J, Ringel F, Bettstetter M, Hoepner I, Rasper M, Gempt J, Koeritzer J, Schmidt-Graf F, Meyer B, Beier CP, Schlegel J. Aldehyde dehydrogenase 1A1--a new mediator of resistance to temozolomide in glioblastoma. Neuro Oncol. 2013; 14: 1452-64. doi: nos270 [pii] 10.1093/ neuonc/nos 270 .

28. Zhao D, Mo Y, Li MT, Zou SW, Cheng ZL, Sun YP, Xiong Y, Guan KL, Lei QY. NOTCH-induced aldehyde dehydrogenase $1 \mathrm{~A} 1$ deacetylation promotes breast cancer stem cells. J Clin Invest. 2014; 124: 5453-65. doi: 10.1172/ JCI76611.

29. Hu Y, Smyth GK. ELDA: extreme limiting dilution analysis for comparing depleted and enriched populations in stem cell and other assays. J Immunol Methods. 2009; 347: 70-8. doi: S0022-1759(09)00195-1 [pii] 10.1016/j. jim.2009.06.008.

30. van der Flier LG, Haegebarth A, Stange DE, van de Wetering M, Clevers H. OLFM4 is a robust marker for stem 
cells in human intestine and marks a subset of colorectal cancer cells. Gastroenterology. 2009; 137: 15-7. doi: S00165085(09)00800-2 [pii] 10.1053/j.gastro.2009.05.035.

31. Powell AE, Wang $\mathrm{Y}$, Li Y, Poulin EJ, Means AL, Washington MK, Higginbotham JN, Juchheim A, Prasad N, Levy SE, Guo Y, Shyr Y, Aronow BJ, et al. The panErbB negative regulator Lrig1 is an intestinal stem cell marker that functions as a tumor suppressor. Cell. 2012; 149: 146-58. doi: S0092-8674(12)00280-2 [pii] 10.1016/j. cell.2012.02.042.

32. Maugeri-Sacca M, Bartucci M, De Maria R. DNA damage repair pathways in cancer stem cells. Mol Cancer Ther. 2012; 11: 1627-36. doi: 10.1158/1535-7163.MCT-11-1040.

33. Oh SC, Park YY, Park ES, Lim JY, Kim SM, Kim SB, Kim J, Kim SC, Chu IS, Smith JJ, Beauchamp RD, Yeatman TJ, Kopetz S, et al. Prognostic gene expression signature associated with two molecularly distinct subtypes of colorectal cancer. Gut. 2012; 61: 1291-8. doi: gutjnl-2011-300812 [pii] 10.1136/gutjnl-2011-300812.

34. Ke J, Wu X, He X, Lian L, Zou Y, Wang H, Luo Y, Wang L, Lan P. A subpopulation of CD24(+) cells in colon cancer cell lines possess stem cell characteristics. Neoplasma. 2012; 59: 282-8. doi: 10.4149/neo_2012_036.

35. Zheng X, Xie Q, Li S, Zhang W. CXCR4-positive subset of glioma is enriched for cancer stem cells. Oncol Res. 2011; 19: 555-61.

36. Hlavata I, Mohelnikova-Duchonova B, Vaclavikova R, Liska V, Pitule P, Novak P, Bruha J, Vycital O, Holubec L, Treska V, Vodicka P, Soucek P. The role of ABC transporters in progression and clinical outcome of colorectal cancer. Mutagenesis. 2012; 27: 187-96. doi: ger075 [pii] 10.1093/ mutage/ger075.

37. Giraldez MD, Lozano JJ, Cuatrecasas M, Alonso-Espinaco V, Maurel J, Marmol M, Horndler C, Ortego J, Alonso V, Escudero P, Ramirez G, Petry C, Lasalvia L, et al. Geneexpression signature of tumor recurrence in patients with stage II and III colon cancer treated with 5'fluoruracil-based adjuvant chemotherapy. Int J Cancer. 2012; 132: 1090-7. doi: 10.1002/ijc.27747.

38. Kahlert C, Gaitzsch E, Steinert G, Mogler C, Herpel E, Hoffmeister M, Jansen L, Benner A, Brenner H, ChangClaude J, Rahbari N, Schmidt T, Klupp F, et al. Expression analysis of aldehyde dehydrogenase 1A1 (ALDH1A1) in colon and rectal cancer in association with prognosis and response to chemotherapy. Ann Surg Oncol. 2012; 19: 4193-201. doi: 10.1245/s10434-012-2518-9.

39. Ishihara Y, Matsunaga K, Iijima H, Hasegawa G, Suzuki T, Sato A, Kobayashi T, Yang M, Hoffman RM. The combination of 5-FU, leucovorin and CPT-11 (FOLFIRI) prolongs survival through inhibition of metastasis in an orthotopic model of colon cancer. Anticancer Res. 2010; 30: 403-8. doi: 30/2/403.

40. Qiao E, Ji M, Wu J, Ma R, Zhang X, He Y, Zha Q, Song $\mathrm{X}$, Zhu LW, Tang J. Expression of the PXR gene in various types of cancer and drug resistance. Oncol Lett. 2013; 5: 1093-100. doi: 10.3892/ol.2013.1149.

41. Chakraborty S, Kanakasabai S, Bright JJ. Constitutive androstane receptor agonist CITCO inhibits growth and expansion of brain tumour stem cells. Br J Cancer. 2011; 104: 448-59. doi: 10.1038/sj.bjc.6606064.

42. Burger PE, Gupta R, Xiong X, Ontiveros CS, Salm SN, Moscatelli D, Wilson EL. High aldehyde dehydrogenase activity: a novel functional marker of murine prostate stem/progenitor cells. Stem Cells. 2009; 27: 2220-8. doi: 10.1002/stem.135.

43. Ginestier C, Hur MH, Charafe-Jauffret E, Monville F, Dutcher J, Brown M, Jacquemier J, Viens P, Kleer CG, Liu S, Schott A, Hayes D, Birnbaum D, et al. ALDH1 is a marker of normal and malignant human mammary stem cells and a predictor of poor clinical outcome. Cell Stem Cell. 2007; 1: 555-67. doi: S1934-5909(07)00133-6 [pii] 10.1016/j.stem.2007.08.014.

44. Landen CN, Jr., Goodman B, Katre AA, Steg AD, Nick AM, Stone RL, Miller LD, Mejia PV, Jennings NB, Gershenson DM, Bast RC, Jr., Coleman RL, Lopez-Berestein G, et al. Targeting aldehyde dehydrogenase cancer stem cells in ovarian cancer. Mol Cancer Ther. 2010; 9: 3186-99. doi: 1535-7163.MCT-10-0563 [pii] 10.1158/1535-7163. MCT-10-0563.

45. Tomita H, Tanaka K, Tanaka T, Hara A. Aldehyde dehydrogenase 1A1 in stem cells and cancer. Oncotarget. 2016; 7:11018-32. doi: 10.18632/oncotarget.6920.

46. Cui JY, Gunewardena SS, Rockwell CE, Klaassen CD. ChIPing the cistrome of PXR in mouse liver. Nucleic Acids Res. 2010; 38: 7943-63. doi: 10.1093/nar/gkq654.

47. Wang H, Venkatesh M, Li H, Goetz R, Mukherjee S, Biswas A, Zhu L, Kaubisch A, Wang L, Pullman J, Whitney K, Kuro OM, Roig AI, et al. Pregnane X receptor activation induces FGF19-dependent tumor aggressiveness in humans and mice. J Clin Invest. 2011.

48. Pondugula SR, Mani S. Pregnane xenobiotic receptor in cancer pathogenesis and therapeutic response. Cancer Lett. 2013; 328: 1-9. doi: S0304-3835(12)00518-6 [pii] 10.1016/j.canlet.2012.08.030.

49. Staudinger JL, Goodwin B, Jones SA, Hawkins-Brown D, MacKenzie KI, LaTour A, Liu Y, Klaassen CD, Brown KK, Reinhard J, Willson TM, Koller BH, Kliewer SA. The nuclear receptor PXR is a lithocholic acid sensor that protects against liver toxicity. Proc Natl Acad Sci U S A. 2001; 98 : 3369-74. doi: 10.1073/pnas.051551698 98/6/3369.

50. Hirsch HA, Iliopoulos D, Tsichlis PN, Struhl K. Metformin selectively targets cancer stem cells, and acts together with chemotherapy to block tumor growth and prolong remission. Cancer Res. 2009; 69: 7507-11. doi: 0008-5472. CAN-09-2994 [pii] 10.1158/0008-5472.CAN-09-2994.

51. Rausch V, Liu L, Kallifatidis G, Baumann B, Mattern J, Gladkich J, Wirth T, Schemmer P, Buchler MW, Zoller M, Salnikov AV, Herr I. Synergistic activity of sorafenib 
and sulforaphane abolishes pancreatic cancer stem cell characteristics. Cancer Res. 2010; 70: 5004-13.

52. Krausova L, Stejskalova L, Wang H, Vrzal R, Dvorak Z, Mani S, Pavek P. Metformin suppresses pregnane X receptor (PXR)-regulated transactivation of CYP3A4 gene. Biochem Pharmacol. 2011; 82: 1771-80. doi: S00062952(11)00674-5 [pii] 10.1016/j.bcp.2011.08.023.

53. Zhou C, Poulton EJ, Grun F, Bammler TK, Blumberg B, Thummel KE, Eaton DL. The dietary isothiocyanate sulforaphane is an antagonist of the human steroid and xenobiotic nuclear receptor. Mol Pharmacol. 2007; 71: 220-9.

54. Bartley AN, Parikh N, Hsu CH, Roe DJ, Buckmeier JA, Corley L, Phipps RA, Gallick G, Lance P, Thompson PA, Hamilton SR. Colorectal adenoma stem-like cell populations: associations with adenoma characteristics and metachronous colorectal neoplasia. Cancer Prev Res (Phila). 2013; 6: 1162-70. doi: 10.1158/1940-6207.CAPR-13-0113.

55. Carpentino JE, Hynes MJ, Appelman HD, Zheng T, Steindler DA, Scott EW, Huang EH. Aldehyde dehydrogenase-expressing colon stem cells contribute to tumorigenesis in the transition from colitis to cancer. Cancer Res. 2009; 69: 8208-15. doi: 10.1158/0008-5472. CAN-09-1132.

56. Kim MP, Fleming JB, Wang H, Abbruzzese JL, Choi W, Kopetz S, McConkey DJ, Evans DB, Gallick GE. ALDH activity selectively defines an enhanced tumor-initiating cell population relative to CD133 expression in human pancreatic adenocarcinoma. PLoS One. 2011; 6: e20636. doi: 10.1371/journal.pone.0020636. 